\title{
Robust simulation-optimization of dynamic-stochastic production/inventory control system under uncertainty using computational intelligence
}

\author{
Amir Parnianifard ${ }^{\mathrm{a}}$, Ali Zemouche ${ }^{\mathrm{b}}$, Muhammad Ali Imran ${ }^{\mathrm{b}}$ and Lunchakorn Wuttisittikulkij ${ }^{c^{*}}$
}

\begin{abstract}
${ }^{a}$ Department of Electrical Engineering, Faculty of Engineering, Chulalongkorn University, Bangkok 10330, Thailand
${ }^{b}$ University of Lorraine, CRAN UMR CNRS 7039, 54400 Cosnes et Romain, France

${ }^{c}$ School of Engineering, University of Glasgow, Glasgow, G12 8QQ, UK

C H R O N I C L E

A B S T R A C T

Article history:

Received June 30, 2020

Received in revised format July 8 ,

2020

Accepted August 302020

Available online

September 22020

Keywords:

Computational Intelligence

Polynomial Regression

Production-Inventory System

Stochastic Control

Robust Simulation-Optimization

In production/inventory control systems, the goal of the controller is to generate sophisticated decisions by controlling the order rate and inventory level. This paper aims at modeling a dynamic-stochastic production/inventory control system under two sources of variability (uncertainty) including uncertainties on demand rate and frustrating rate. The study deals with obtaining a robust optimal design of a Proportional-Integral-Derivative (PID) controller in in the stochastic control system. For this purpose, a new robust simulation-optimization method in the class of computational intelligence is proposed. To cope with the unknown distribution of uncertainty, the crossing weighted uncertainty scenarios are combined with the proposed method. Within this study, a new sequential robust efficient global optimization is proposed to make a trade-off between optimal and robustness terms in final optimization results. Finally, a numerical case with simulation experiments is conducted to demonstrate the advantages of the proposed policy in terms of optimal result, robustness, and computational cost.
\end{abstract}

\section{Introduction}

Optimal control theory is a branch of mathematics developed to find optimal ways to control a dynamic system. One of the most important control problems in engineering design applications is the Production/Inventory (P/I) control system (Neck, 1984; Sethi, 2019). A block diagram representation of classical inventory and order-based production control system is schematically shown in Fig. 1 (Grubbström \& Wikner, 1996; White, 1999; Wikner, 1994). In P/I control systems, the aim of the controller is to generate sophisticated decisions that control the order rate and the inventory level based on trade-offs between P/I cost and customer satisfaction (Ortega \& Lin, 2004). Order policy can be defined as PID controller systems. This kind of control for the P/I system is frequently used in a variety of applications (Grubbström \& Wikner, 1996; Ortega \& Lin, 2004). In searching for an effective method for planning and optimizing an inventory control system, the concepts of system dynamics are particularly useful (Towill \& Yoon, 1982). The use of feedback to achieve a better performance is necessary for both inventory and process controls. However, in some models it is necessary to solve the global optimization problem by considering the 'best' parameter settings within all loops simultaneously (Towill \& Yoon, 1982). The standard inventory management policies based on traditional Economic Order Quantity (EOQ) approaches with a judiciouslydesigned PID controller in the case of a single inventory in a supply chain has been illustrated in (Rivera \& Pew, 2005). It is also claimed that a well-tuned PID-based policy is able to generate effective decisions on orders that ultimately reduce the need for safety stock by eliminating backorders.

* Corresponding author

E-mail address: Lunchakorn.W@chula.ac.th (L. Wuttisittikulkij)

C 2020 by the authors; licensee Growing Science.

doi: $10.5267 /$ j.uscm.2020.9.002 


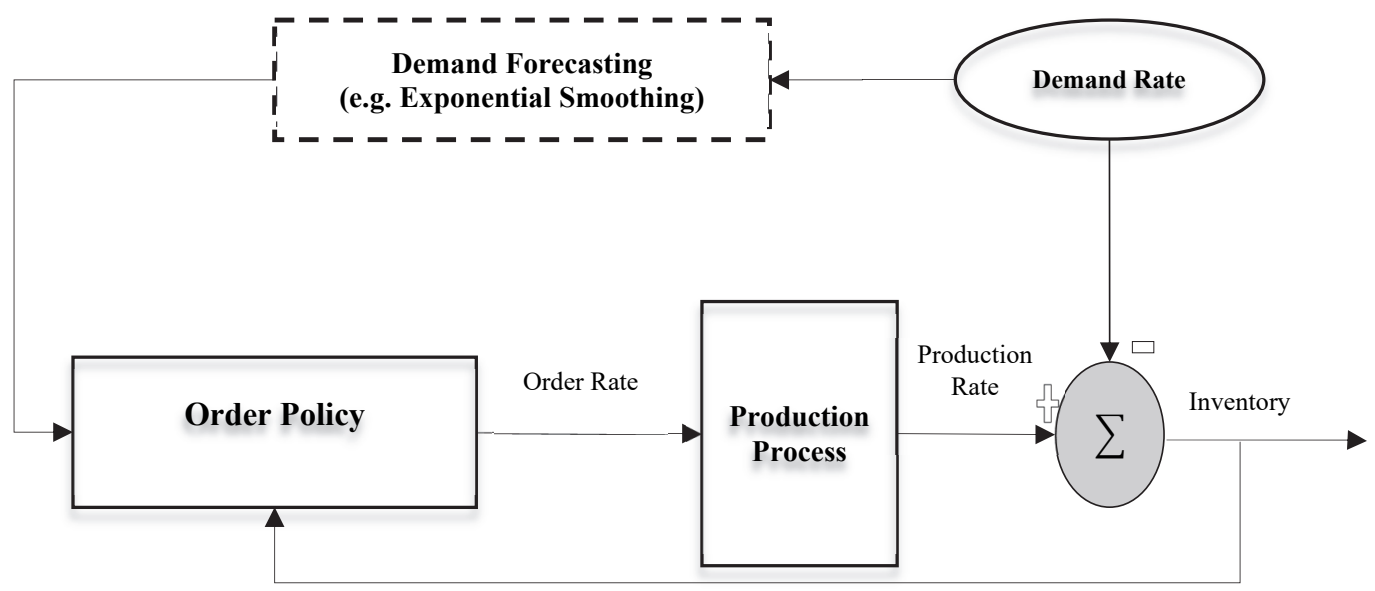

Fig. 1. Traditional block diagram representation of a production-inventory system.

The application of the control theory in inventory-production systems has been illustrated in different studies, see (Azarskov et al., 2013, 2017; Salcedo et al., 2013; Hasani et al., 2018; Neck, 1984; Schwartz \& Rivera, 2010; Sourirajan et al., 2008; Tao et al., 2017; White \& Censlive, 2016). Uncertainty in the dynamic-stochastic P/I control system has been the focus of different studies in the literature, see (Pishvaee et al., 2011; Tang et al., 2019; Van Landeghem \& Vanmaele, 2002). Analyzing and optimizing the simulation model particularly under uncertainty in real engineering practice have been still computationally expensive and time-consuming (Barros et al., 2010; Dellino et al., 2009; Parnianifard et al., 2019; Parnianifard et al., 2018a). If the physical system can be derived hardly, simulation experiments (also known as computer experiments) can be used instead (Meshram \& Kanojiya, 2012). In fact, computer experiments are able to evaluate complex systems, either deterministic or stochastic while eliminating computational complexity (Figueira \& Almada-Lobo, 2014). Essentially, control system design is a challenge due to the complexity of dynamic control problems (Agrell \& Wikner, 1996; Ang et al., 2005; Jones \& Hengue, 2009). Some traditional methods for optimal control of dynamic systems have been reported in (Åström et al., 1993; Cohen, 1953; Hang et al., 1991; Wang et al., 1999; Ziegler \& Nichols, 1942). However, for 'expensive optimizations' such as computer-aided design optimization or simulation-based optimization using computer experiments with high computational cost, traditional optimization methods may perform poorly or may even fail to obtain a satisfactory solution within the allocated computational budget. To avoid this, researchers turn to computational intelligence methods such as agent-based algorithms, fuzzy logic, artificial neural networks, and surrogates techniques, see (Ansari \& Hou, 2012; Nakayama et al., 2002; Tenne \& Goh, 2010). In general, computational intelligence does not adopt that an algebraic description of the true model is available. However, the model may be available as a black-box that only allows to approximate the objective and constraints as input/output set of data. To overcome such difficulties, researchers have applied surrogate-based learning methods (Ali Asghar, 2019; Parnianifard et al., 2019b; Wang \& Shan, 2007). The application of different surrogates in optimal control theory has been studied in the literature. The studies in the literature have covered topics like different orders of Polynomial Regression (PR) (Camcioğlu et al., 2017; Hwang et al., 2007; Parnianifard et al., 2018b), Radial Basis Function (RBF) (Chen \& Kuo, 2017; Ho et al., 2017; Shah et al., 2011), and Kriging surrogate (Liu et al., 2016; Liu et al., 2011; Parnianifard et al., 2018; Parnianifard et al., 2018). There are different ways of optimizing not only the control systems via a mathematical model or direct-simulation model, but also computational intelligence using surrogate-based learning methods (Faruq et al., 2018; Ryabchikov \& Ryabchikova, 2017). Fig. 2 summarizes different techniques to optimize control systems, while the dash arrows show the path that in the current study is followed to achieve the optimal design of the P/I control system. Most existing PID tuning methods increase robustness against disturbances which arise from the load (deterministic control system), while uncertainty in the plant's parameters (stochastic control system) has been ignored. This gap may result in suboptimal results because of changes in load parameters. To best of our knowledge, there is a lack of studies implanting a PID controller in the P/I system when both load and uncertainty in a dynamic control system are sources of variability in output. In our study, we assume two sources as uncertain factors. The first is the demand rate and the second factor is the portion of inventory which is shifted to the next time step (that is called frustrating rate here). Both factors follow the unknown probability distribution. Moreover, a method is developed for such a case to consider uncertainty with unknown distribution. In the projected P/I control system, we also consider the reliability of the production rate due to the failure rate and breakdown based on the step time. In our proposed promising technique, we construct a dynamic-stochastic control system to reduce the effect of the production leadtime by delivering products to the customer once the demand recorded. We develop an optimal control theory by implanting a PID controller in a dynamic and stochastic P/I system. We apply a computational intelligence approach to reduce the computational complexity (number of function evaluations) in the optimal tuning of the PID controller. For this purpose, we propose a new approach by applying the modern sampling design method (e.g. space-filling methods) and surrogate (e.g. polynomial regression) to learn and be able to approximate the behavior of a dynamic system. In order to consider uncertainty in the model with unknown distribution, we develop our method using combined robust design and crossing 
weighted uncertainty scenarios (distribution-free method) proposed in (Parnianifard et al., 2019a). As another contribution of this paper, we propose a new framework for robust efficient global optimization to derive a sequential optimization by making a trade-off between optimization and robustness.



Fig. 2. Different ways for optimizing a control system based on mathematical, simulation, or surrogate

The rest of this paper is organized as follows. A framework for the dynamic-stochastic production-inventory control system which is considered in this study is elaborated in Section 2. Section 3 explains the materials and methods required for performing the proposed approach as a simulation-optimization based on computational intelligence. A numerical case is studied and discussed in Section 4 in order to show the application of proposed algorithm in optimal control of the dynamicstochastic P/I System. Finally, this paper is concluded in Section 5.

\section{Dynamic-Stochastic P/I Control System}

PID controller employs three terms namely proportional, integral, and derivative terms to reduce an error signal $(e)$ to be closer to zero. The output of a PID controller equal to the control input of the plant in the time-domain is:

$$
u(t)=K_{p} e(t)+K_{i} \int_{n}^{t} e(t) d t+K_{d} \frac{d e(t)}{d t}
$$

where $u(t)$ is the overall control function. $K_{p}, K_{i}$, and $K_{d}$ denote the coefficients for the proportional, integral, and derivative terms respectively. The appropriate function of PID strongly depends on the allocated value of each gain parameters $\left(K_{p}, K_{i}\right.$, and $\left.K_{d}\right)$. In order to evaluate the performance of the PID controller, a common creation namely Integral Square Error (ISE) is used. It should be noted that this creation is associated with all time-response parameters including rise time, steady-state error, settling time, and overshoot (Astrom \& Hagglund, 1995). The mathematical features of ISE performance creation in time domain $t$ are defined as below:

$$
I S E=\int_{0}^{T_{S}} e(t)^{2} d t=\int_{0}^{T_{S}}(y(t)-S)^{2} d t
$$

where $y(t)$ is the response (output) at time domain $0 \leq t \leq T_{S}$ and $S$ is the desired setpoint for the response of the model. A good implementation of the control theory applied to production-inventory control has been presented by (Dejonckheere et al., 2003; Schwartz \& Rivera, 2010; White, 1999; Wikner, 1994). In the mentioned studies, an exponential smoothing has been used to obtain the average sales consumption as a function of the sales (demand) rate in optimal control of dynamic P/I system (see Fig. 1). However, in the traditional control overview, any changes due to uncertainty (source of variability) in demand rate can change the optimal results to inferior. Here, we develop a robust PID tuning model that provides robustness in the gain parameters to make them insensitive to the sources of variability (e.g. uncertainty in demand). In our proposed dynamic control system, we consider a factory producing a single homogeneous good and having a finished goods warehouse. In this study, we design the dynamic-stochastic P/I model as below:

$$
I(t)=(1-\widetilde{\alpha}(t)) \cdot I(t-1)+\exp (-\lambda \cdot t) \cdot O(t)-\widetilde{D}(t)
$$


where $I(t)$ indicates the inventory level at time $t$, and $\widetilde{\alpha}(t),(0 \leq \widetilde{\alpha} \leq 1)$ shows an uncertain portion of inventory that cannot use in the next time step due to some reasons like damaging or frustrating (we called $\widetilde{\alpha}$ as a frustrating rate here). We assume that $\widetilde{\alpha}$ is the first uncertain factor and follows unknown probability distribution. The optimal order policy $O(t)$ is designed by the PID controller. The demand rate $\widetilde{D}(t)$ is assumed as the second uncertain factor with an unknown probability distribution. In this model, we consider failure and breakdown rate of the product that increased by passing of the time. In order to keep the productive reliability, we assume that $\beta=\exp (-\lambda . t),(0 \leq \lambda \leq 1)$ follows a nonlinear exponential distribution. It means that only $\beta(0 \leq \beta \leq 1)$ portion of the order policy is produced by the production process in each time step. In addition, production rate $P(t)$ on time step $t$ is computed by $P(t)=\beta . O(t)$. The block diagram representation of our proposed dynamic-stochastic P/I control system is shown in Fig. 3 .



Fig. 3. Block diagram representation of the stochastic PID controller in the P/I control system under uncertainty in demand and frustrating rate. This model aims to reduce lead time to zero. The PID gain parameters $\left(\boldsymbol{K}_{\boldsymbol{p}}, \boldsymbol{K}_{\boldsymbol{i}}, \boldsymbol{K}_{\boldsymbol{d}}\right)$ tuned robustly against source of variability (uncertainty).

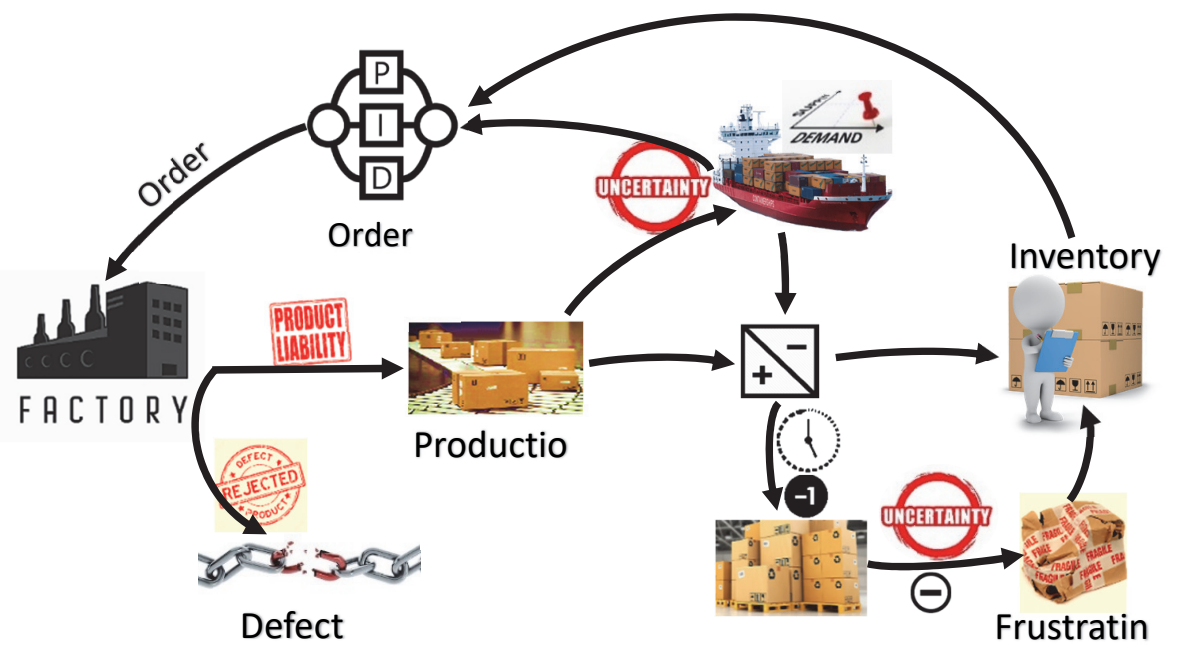

Fig. 4. Schematic representation of the dynamic-stochastic $\mathrm{P} / \mathrm{I}$ control system under uncertainty in demand and frustrating rate. Product reliability is considered in the model. Order policy is defined based on proportional-derivative-integral controller.

It should be noted that this model aims at eliminating the effect of production lead-time by delivering products to the customer once the demand recorded. For this purpose, in the control system, we define the setpoint (desired inventory level) at the same level as the demand level. Moreover, in each time step, the desired setpoint may change regarding uncertainty (the source of variability) in demand and the frustrating rate. Moreover, we look for robust gain parameters $\left(K_{p}, K_{i}, K_{d}\right)$ that 
are insensitive against sources of variability in the control model. It is worth noting that due to two uncertain factors, this variability is discovered in two parts of the system. The first part is the physical load parameters that fluctuates due to uncertainty in both demand and frustrating rate, and the second part is the desired setpoint that fluctuates due to uncertainty in demand rate. In this model, we design the robust optimal tuning of order policy (PID controller) that is sensitive against changeability in the source of variability (uncertain factors). Schematic representation of the dynamic-stochastic P/I control system under uncertainty in demand and frustrating rate considering reliability in production is shown in Fig. 4.

\section{Materials and Methods}

In this section, the proposed promising technique namely Simulation-Optimization based on Computational Intelligence (SOCI) is specified for robust tuning of the PID controller in dynamic P/I control system. For this purpose, we first briefly explain the materials used in the proposed algorithm. Then, the procedure of SOCI in the P/I control system is sketched.

\subsection{Polynomial Regression (PR)}

Commonly, the main motivation of PR for true approximation function is based on Taylor series expansion around a set of design points (Myers et al., 2016). The general overview of the first-order PR model is shown as:

$$
y=f(X)=\hat{\beta}_{0}+\sum_{i=1}^{k} \hat{\beta}_{i} x_{i}+\varepsilon
$$

where $k$ is the number of design variables. Most times, the curvature of the response surface is stronger than the first order PR model, so it can be approximated with the interaction terms. Therefore, a second-order (quadratic) model can be employed:

$$
y=f(X)=\hat{\beta}_{0}+\sum_{i=1}^{k} \hat{\beta}_{i} x_{i}+\sum_{i=1}^{k} \hat{\beta}_{i i} x_{i}^{2}+\sum_{i=1}^{k} \sum_{i<i^{\prime}=2}^{k} \hat{\beta}_{i i^{\prime}} x_{i} x_{i^{\prime}}+\varepsilon
$$

where $\widehat{\beta}_{0}, \hat{\beta}_{i}, \hat{\beta}_{i i}$ and $\hat{\beta}_{i i}$, are unknown regression coefficients and the term $\varepsilon$ is the usual random error (noise) component, see (Myers et al., 2016).

\subsection{Latin Hypercube Sampling (LHS)}

Here, the LHS technique is used to design the required training sample points (also called simulation experiments). LHS was first introduced by (McKay et al., 1979). This technique has been developed based on space-filling properties and producing random points. It is a strategy to generate and permute random points into all the portions of the design space. In general, for $n$ input variables, $m$ sample points are produced randomly into $m$ intervals or scenarios (with equal probability), for more information see (Sacks et al., 1989; Viana, 2016).

\subsection{Distribution-free uncertainty scenarios}

Mostly, in the real world of an engineering problem, there is a lack of appropriate historical data that can be used for estimating uncertainty distribution. Here, inspired by (Parnianifard et al., 2019a), in dealing with the unknown probability distribution of uncertainty, we apply crossing weighted uncertainty scenarios. Let assume $s=(1,2, \ldots, l)$ is the vector of sample points (input combination), and each input combination $(s)$ repeat $r=(1,2, \ldots, m)$ times based on uncertainty scenarios, moreover, $Y$ is the $l \times m$ matrix of simulation's outputs. So, mean $\overline{y_{s}}$ and Standard Deviation $\sigma_{\mathrm{s}}(\mathrm{SD})$ of the simulation model can be computed by following equations:

$$
\begin{aligned}
& \bar{y}_{s}=\sum_{r=1}^{m} w_{r} \cdot y_{s r}, \text { for }(s=1,2, \ldots, l) \\
& \sigma_{\mathrm{s}}=\sqrt{\sum_{r=1}^{m} w_{r} \cdot y_{s r}^{2}-\left(\sum_{r=1}^{m} w_{r} \cdot y_{s r}\right)^{2}}, \text { for }(s=1,2, \ldots, l)
\end{aligned}
$$

The distribution-free formulation for computing $w_{r},(r=1,2, \ldots, m)$ can be obtained based on the effect of each uncertainty scenario on output over input combination, as below.

$$
w_{r}=\frac{\sum_{s=1}^{l}\left[\left(y_{s r}-\overline{y_{r}}\right)^{2}+\left(y_{s r}-\overline{\bar{y}}\right)^{2}\right]}{\sum_{r=1}^{m} \sum_{s=1}^{l}\left[\left(y_{s r}-\overline{y_{r}}\right)^{2}+\left(y_{s r}-\overline{\bar{y}}\right)^{2}\right]}
$$

where 


$$
\overline{y_{r}}=\frac{1}{s} \sum_{s=1}^{l} y_{s r} \quad \text { and } \quad \overline{\bar{y}}=\frac{1}{s \times m} \sum_{s=1}^{l} \sum_{r=1}^{m} y_{s r}
$$

Greater value of $w_{r}$ represents more effects of $r^{\text {th }}$ uncertainty scenario on output variation as well as deviation from the overall mean. This model can handle the unavailability of known distribution for uncertainty in a model, see (Parnianifard et al., 2019a).

\subsection{Augmented robust efficient global optimization}

The efficient global optimization method has been developed in engineering design problems to adaptively improve local and global search of optimal points (i.e. control a trade-off between exploration and exploitation properties), see (Havinga et al., 2017; Jurecka, 2007). These methods are combined with two main parts. The first statistical part consists of the design of experiments and surrogate techniques and the second part involves evolutionary algorithms (Havinga et al., 2017; Jurecka, 2007). If the arbitrary $y_{c}$ is considered, an improvement function over $y_{b}$ is defined as $\max \left\{0,\left(y_{b}-y_{c}\right)\right\}$. A common formulation of efficient global optimization (also called expected improvement creation) is as below:

$$
E I(c)=\left(\bar{y}_{b}-\bar{y}_{c}\right) \Phi\left(\frac{\bar{y}_{b}-\overline{y_{c}}}{\sigma_{c}}\right)+\sigma_{c} \varnothing\left(\frac{\bar{y}_{b}-\bar{y}_{c}}{\sigma_{c}}\right)
$$

where $\Phi$ and $\emptyset$ depict the Cumulative Distribution Function (CDF) and Probability Density Function (PDF) of a standard normal distribution respectively. The first phrase $(\Phi)$ in Eq. (10) is related to local search and the second phrase $(\varnothing)$ is related to a global search. The expressions $\overline{y_{c}}$ and $\sigma_{c}$ depict the mean and SD of the output in the candidate point respectively. The weighted formulation of Eq.(10) has been suggested by (Sóbester et al., 2004) to capture the tendency of formulation to create local and global search. However, Eq.(10) cannot support the stochastic randomness of the current optimum point while ignoring the SD (prediction error) at the current optimal point (Jurecka et al., 2007). Additionally, in Eq. (10), the aim is to increase the optimal results sequentially, when the point with smaller mean $\left(\overline{y_{c}}\right)$ is investigated as compared to the current best point $\left(\bar{y}_{b}\right)$. However, this formulation considers obtaining optimal result that may not be robust. It means that Eq. (10) cannot guarantee to find the robust optimal point with small variability $\left(\sigma_{c}\right)$. Therefore, we investigate a new formulation to search for the robust optimal point when making a trade-off between optimization and robustness against source of variability. Here, we expand the application of the efficient global optimization to handle the framework of robust design optimization. We introduce a Robust Expected Improvement (REI) criterion as a new robust efficient global optimization formulation. In the proposed criterion, a trade-off between optimization and robustness is attended. If the output for the current best point and candidate point are assumed $\left.\tilde{y}_{b} \sim N\left(\bar{y}_{b}, \sigma_{b}^{2}\right)\right)$ and $\tilde{y}_{c} \sim N\left(\bar{y}_{c}, \sigma_{c}^{2}\right)$ respectively, then:

$$
R E I(c)=\exp \left(\frac{\sigma_{b}-\sigma_{c}}{\sigma_{\max }}\right)\left[\left(\bar{y}_{b}-\overline{y_{c}}\right) \Phi\left(\frac{\bar{y}_{b}-\overline{y_{c}}}{\sigma_{b}+\sigma_{c}}\right)+\left(\sigma_{b}+\sigma_{c}\right) \emptyset\left(\frac{\bar{y}_{b}-\overline{y_{c}}}{\sigma_{b}+\sigma_{c}}\right)\right],
$$

where $\sigma_{\text {max }}$ is a user-defined magnitude that shows the largest SD (variability) of the model. In our proposed formulation in Eq.(11), we add a new expression $\exp \left(\frac{\sigma_{b}-\sigma_{c}}{\sigma_{\max }}\right)$ to adjust the amount of variability in a new candidate point as compared to the current best point. Hence, the Eq.(11) would be large when the response for new candidate point is strongly better (smaller mean) and also has the smaller SD as compared with a current best point, (i.e. $\bar{y}_{b}>\bar{y}_{c}$ and $\sigma_{b}>\sigma_{c}$ ).

\section{- Updating procedure}

To derive an optimization procedure sequentially, we first obtain the initial best point inspiring the Taguchi loss function (Del Castillo \& Montgomery, 1993; Phadke, 1989) using $L=\left(\overline{y_{s}}-T\right)^{2}+\sigma_{s}^{2}$, where $T$ shows the target value for simulation output and $\bar{y}_{s}$ and $\sigma_{s}^{2}$ are obtained by Eq.(6) and Eq.(7). The smaller value in loss function depicts the optimal point with higher insensitivity to source of variability (robustness). In the search for the next best point among all the candidate points, the point with maximum $R E I(\mathrm{c})$ term in Eq.(11) is selected and replaced with the best point so far (in first step is initial best point). This procedure is continued until Max REI $-0 \leq \varepsilon$, where $\varepsilon$ is a user-defined threshold. However, to find the candidate points (also called neighbor points) around the current best point, different deign of experiments (DOE) strategies can be employed (e.g. full factorial design, fractional factorial design, etc.). In this study, three design variables including PID gain parameters $\left(K_{p}, K_{i}, K_{d}\right)$ are considered. However, for models with small number of design variables (e.g. below five variables), two-level full factorial design or fractional factorial design can be used to define $t$ candidate points around current best point, see (Myers et al., 2016; Rutten, 2015). If $i=(1,2, \ldots, n)$ shows the number of design variables in the model, based on two-level full factorial method, the number of candidates in vicinity of best point is $t=2^{i}$. If $x_{i}^{b}$ denotes the value of $i^{t h}$ design variable in the current best point, the upper level $\left(u_{i}^{b}\right)$ and the lower level $\left(l_{i}^{b}\right)$ for each design variable based on two-level full factorial design around center $\left(x_{i}^{b}\right)$ can be computed by $x_{i}^{b}\left(1 \mp \beta_{i}\right)$, where $0 \leq \beta_{i} \leq 1$. Fig. 5 illustrates the two-level full factorial design around current best point for a model with two design variables (four separate new sample points are considered as sets of candidate points). 
3.5 The procedure of SOCI algorithm

The overall proposed SOCI algorithm proceeds in the following steps:

Step 1: Design a combined array matrix by integrating both $n_{x}$ design and $n_{z}$ uncertain variables with dimensions $\left(N_{S} \times\left[n_{x}+n_{z}\right]\right)$, where $N_{S}$ is the number of the training sample points.

Here, we assume two uncertain variables including demand rate and frustrating rate and three design variables including PID gain parameters $\left(K_{p}, K_{i}, K_{d}\right)$.

Step 2: Run the simulation model for each training point and gain simulation output $\left(y_{s}\right)$.

In this study, regarding Eq.(2), the ISE performance creation in time domain $t$ is considered as the simulation output.

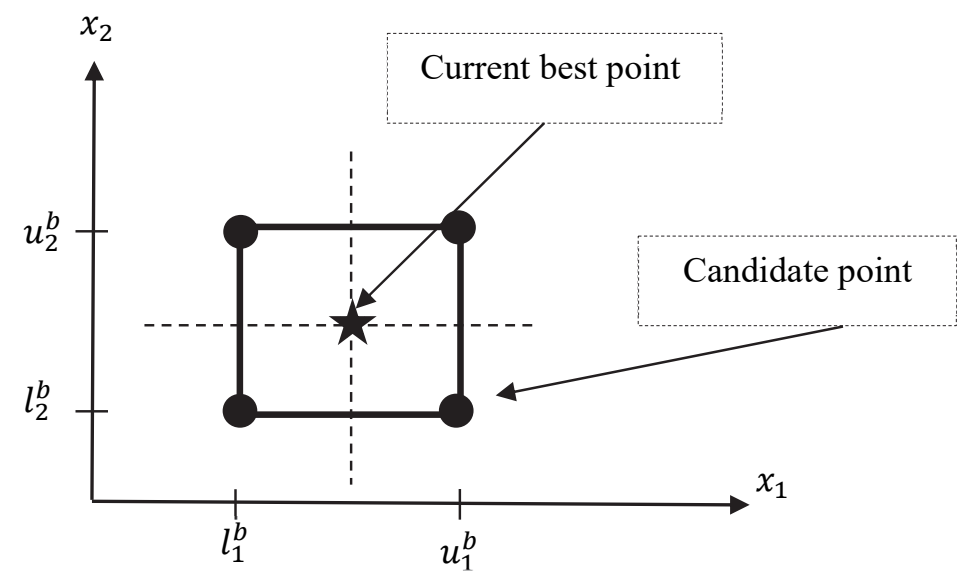

Fig. 5. Two-level full factorial design for problem with two design variables in order to design candidate points for $\boldsymbol{t}=\mathbf{1}, \mathbf{2}, \mathbf{3}, \mathbf{4}$ surrounding current best point

Step 3: Fit one surrogate (e.g. PR in this paper) over obtained simulation input/output data, $\widehat{Y}=\widehat{f}(X, Z)$.

Step 4: Design crossed array with dimensions $N_{B}=s \times r$ as below:

An inner array matrix with dimensions $\left(s \times n_{x}\right)$ when $s$ is the number of sample points for design variables.

An outer array matrix with dimension $\left(r \times n_{z}\right)$ when $r$ is the number of sample points (scenarios) for uncertain variables.

Step 5: Run the surrogate that is fitted previously regarding Step 3 for each crossed $(s \times r)$ combination and predict the relevant output $\widehat{y}_{s r}$, (i.e. surrogate is used instead of the original simulation model to collect relevant input/output data).

Step 6: Compute mean $\overline{y_{s}}$ and variance $\sigma_{s}^{2}$ over outputs data obtained from Step 5 using Eq.(6) till Eq.(9).

Step 7: Fit one surrogate for mean and another for the standard deviation of output.

Step 8: Construct the formulation of robust efficient global optimization regarding Eq.(11) for sequential improvement and compute robust optimal point.

\section{Application of SOCI in optimal control of dynamic-stochastic P/I System}

4.1 Numberical case study

Here, a numerical case in simulation-based optimization of the stochastic P/I control system using the SOCI method is presented for robust optimal tuning of the PID controller as elucidated in Section 0. In this numerical case, we consider problem instance with the parameters as defined in Table 1.

Table 1

Physical parameters in the stochastic-dynamic P/I control system.

\begin{tabular}{cll}
\hline Parameter & Title & Value \\
\hline$K_{n}$ & & Design variable \\
$K_{i}$ & PID gain parameters & Design variable \\
$K_{d}$ & & Design variable \\
$\widetilde{\alpha}(t)$ & Frustrating rate & Uncertain variable with unknown probability distribution in ranges \\
$\widetilde{D}(t)$ & Demand rate & Uncertain variable with unknown probability distribution in ranges [10,15] \\
$\lambda$ & Shape parameter (exponential & 0.05 \\
\hline
\end{tabular}


The MATLAB $R /$ Simulink toolbox was used to construct a simulation model and collect associated experimental data. We evaluated PID controller performance with the ISE measure in the time domain $0 \leq t \leq 30$ seconds. We uniformly produce random numbers for uncertain variables (demand and frustrating rates) and tune the model with MATLAB ${ }^{\circledR} /$ Simulink, PID tuning toolbox. It provides the PID gain parameters in $K_{p}=0.08, K_{i}=31.98, K_{d}=0$. In order to make the results gained by SOCI method comparable with the results obtained from MATLAB ${ }^{\circledR} /$ Simulink, PID tuning toolbox, we define the design ranges for $K_{p}, K_{i}$, and $K_{d}$ as follows:

$$
K_{p} \in[0,2], K_{i} \in[30,34], \quad K_{d} \in[0,2]
$$

In continue, for the current case study, we follow the procedures explained in Section 3.5 systematically. Regarding the predefined ranges of three design variables $\left(K_{p}, K_{i}, K_{d}\right)$ and two uncertain variables $(\widetilde{D}, \tilde{\alpha})$, we design a combined array for a total of five variables by producing $N_{S}=50$ training sample points using the LHS method. It should be noted that if $k$ is number of input variables, in order to construct surrogate, the sufficient size of training sample points needs to be at least $10 \mathrm{k}$, see (Jin et al., 2001). Then, we run the simulation model for each input combination and collect associated simulation output (i.e. here we compute the ISE measure for each input combination). The magnitudes of ISE for 50 sample points (input combinations) over each input variable are shown in Fig. 6. Over the obtained input/output data (50 input combinations and relevant output), we fit the PR surrogate. Analysis of variance for response surface suggests a quadratic model with R-Squared 0.94 and Adjusted R-Squared 0.91. The mathematical equation of the constructed PR surrogate is as below:
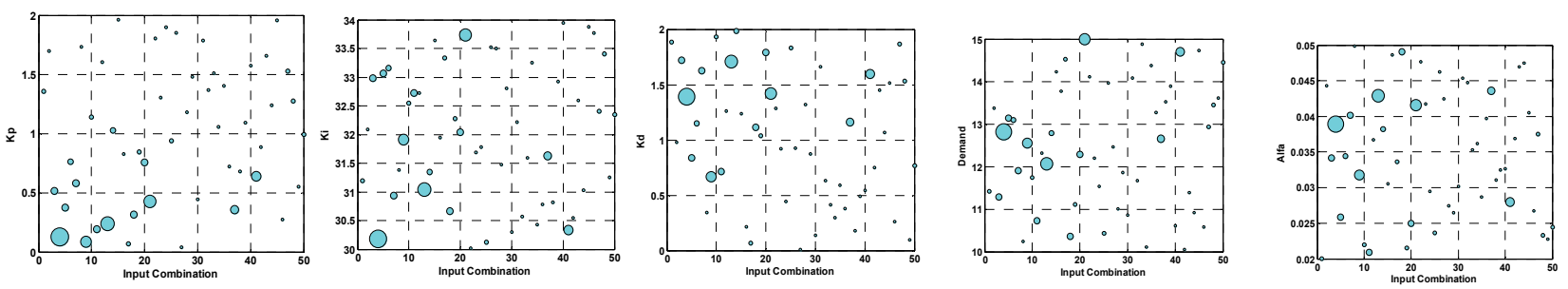

Fig. 6. The magnitudes (bubble size) of simulation output (ISE) for 50 sample points (input combinations) over each input variables (three design variables $\left(K_{p}, K_{i}, K_{d}\right)$ and two uncertain variables $\left.(\widetilde{D}, \widetilde{\alpha})\right)$

$$
\begin{aligned}
I S E=-1120.02 & -555 K_{p}+66.78 K_{i}-48.07 K_{d}+62.75 \widetilde{D}+3928.22 \widetilde{\alpha}+17.84 K_{p} K_{i}-94.37 K_{p} K_{d} \\
& -18.35 K_{p} \widetilde{D}-246.32 K_{p} \widetilde{\alpha}+4.47 K_{i} K_{d}-2.94 K_{i} \widetilde{D}-375.75 K_{i} \widetilde{\alpha}+10.01 K_{d} \widetilde{D} \\
& +300.75 K_{d} \widetilde{\alpha}+700.71 \widetilde{D} \widetilde{\alpha}+98.45 K_{p}{ }^{2}-0.72 K_{i}{ }^{2}-32.22 K_{d}{ }^{2}+1.10 \widetilde{D}^{2}-5735.11 \widetilde{\alpha}^{2}
\end{aligned}
$$

In the next step, we produce a bigger sample set by crossing an LHS design (150 combinations) for three design variables $\left(K_{p}, K_{i}, K_{d}\right)$ and an LHS design (50 combinations) for two uncertain variables $(\widetilde{D}, \widetilde{\alpha})$. So, the overall design size is $N_{B}=$ $150 \times 100=15,000$. Notice that the bigger value for the overall design $\left(N_{B}=15,000\right)$ does not imply a computationally expensive task as compared to the smaller design $\left(N_{S}=50\right)$, because we use this bigger design to compute surrogate predictions instead of running the original simulation model.

We compute the surrogate predictions for predefined $N_{B}$ input combinations using the PR surrogate that is constructed over the smaller set of simulation experiments ( $N_{S}$ input combinations), see Eq.(12). Next, we compute the sample mean of ISE predictions (see Eq.(6)) and the sample SD of ISE (see Eq.(7)) using crossing weighted uncertainty scenarios supporting the unknown probability distribution, see Eq.(8) and Eq.(9), see Fig. 7. Over the obtained input/output set of data, we fit one PR surrogate for the mean of ISE and another PR surrogate for SD of ISE. Analysis of variances over both sets of data recommends quadratic PR model for the mean of ISE and cubic PR model with R-Squared 0.99 for both fitted surrogates. The mathematical equations of fitted PR surrogate for the mean of ISE and SD of ISE are as below:

$$
\begin{aligned}
& \text { Mean_ISE }=336.37-801.39 K_{p}+15.28 K_{i}+92.28 K_{d}+17.84 K_{p} K_{i}-94.37 K_{p} K_{d}+4.47 K_{i} K_{d} \\
& +98.45 K_{p}{ }^{2}-0.72 K_{i}^{2}-32.22 K_{d}{ }^{2} \\
& \begin{aligned}
& S D \_I S E=-2581.82+261.68 K_{p}+257.32 K_{i}+29.61 K_{d}-18.50 K_{p} K_{i}+86.30 K_{p} K_{d}-0.37 K_{i} K_{d} \\
&- 79.05 K_{p}{ }^{2}-8.27 K_{i}{ }^{2}-23.20 K_{d}{ }^{2}-2.74 K_{p} K_{i} K_{d}+2.57 K_{p}{ }^{2} K_{i}-7.81 K_{p}{ }^{2} K_{d} \\
&+ 0.30 K_{p} K_{i}{ }^{2}+3.78 K_{p} K_{d}{ }^{2}-0.003 K_{i}{ }^{2} K_{d}+0.70 K_{i} K_{d}{ }^{2}+4.48 K_{p}{ }^{3}+0.087 K_{i}{ }^{3} \\
&- 0.06 K_{d}{ }^{3}
\end{aligned}
\end{aligned}
$$

Fig. 8 and Fig. 9 plot the square error and 3D surface plots of fitted PR surrogates over the mean of ISE and SD of ISE respectively. 

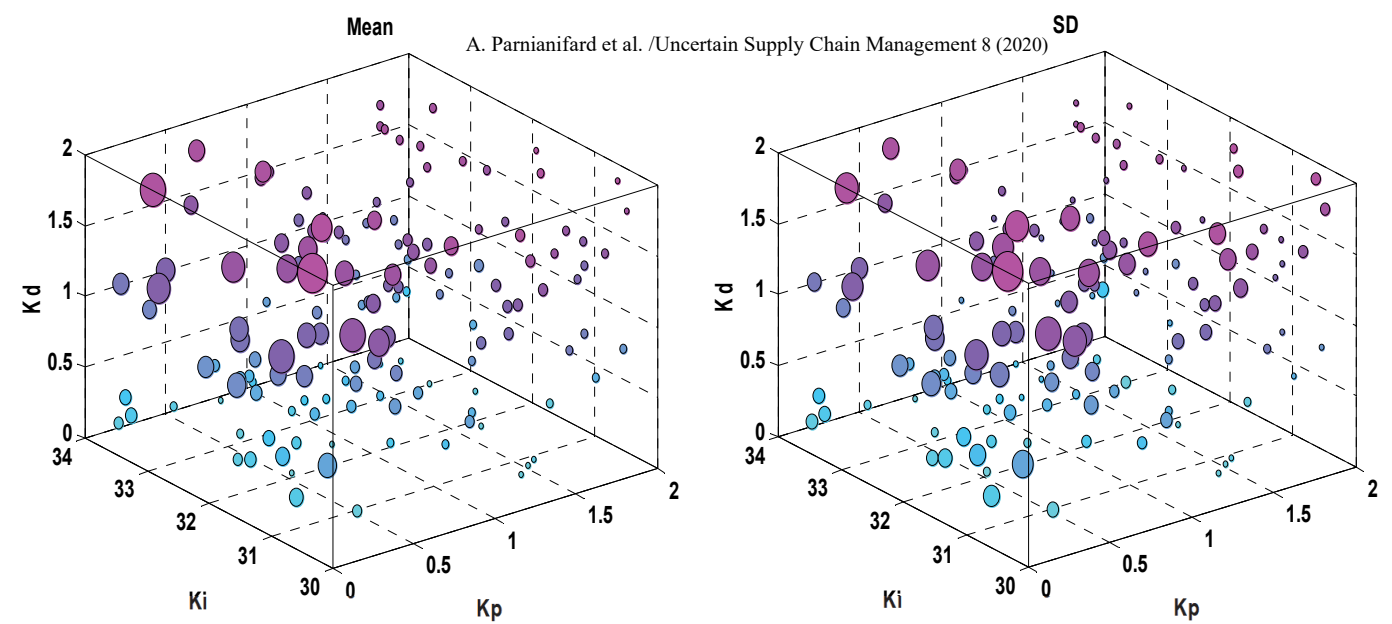

Fig. 7. Mean and SD of ISE for 150 sample points obtained by varying uncertain variables over 100 different scenarios. PR surrogate is used instead of original simulation model to estimate relevant ISE output for each combination of sample point over design variables and uncertainty scenarios (15,000 different combinations).


Fig. 8. The square error and 3D surface plots of fitted PR surrogate over mean of ISE. Surfaces plotted for two design variables (PID gain parameters) when third one stands on center of its design range. 

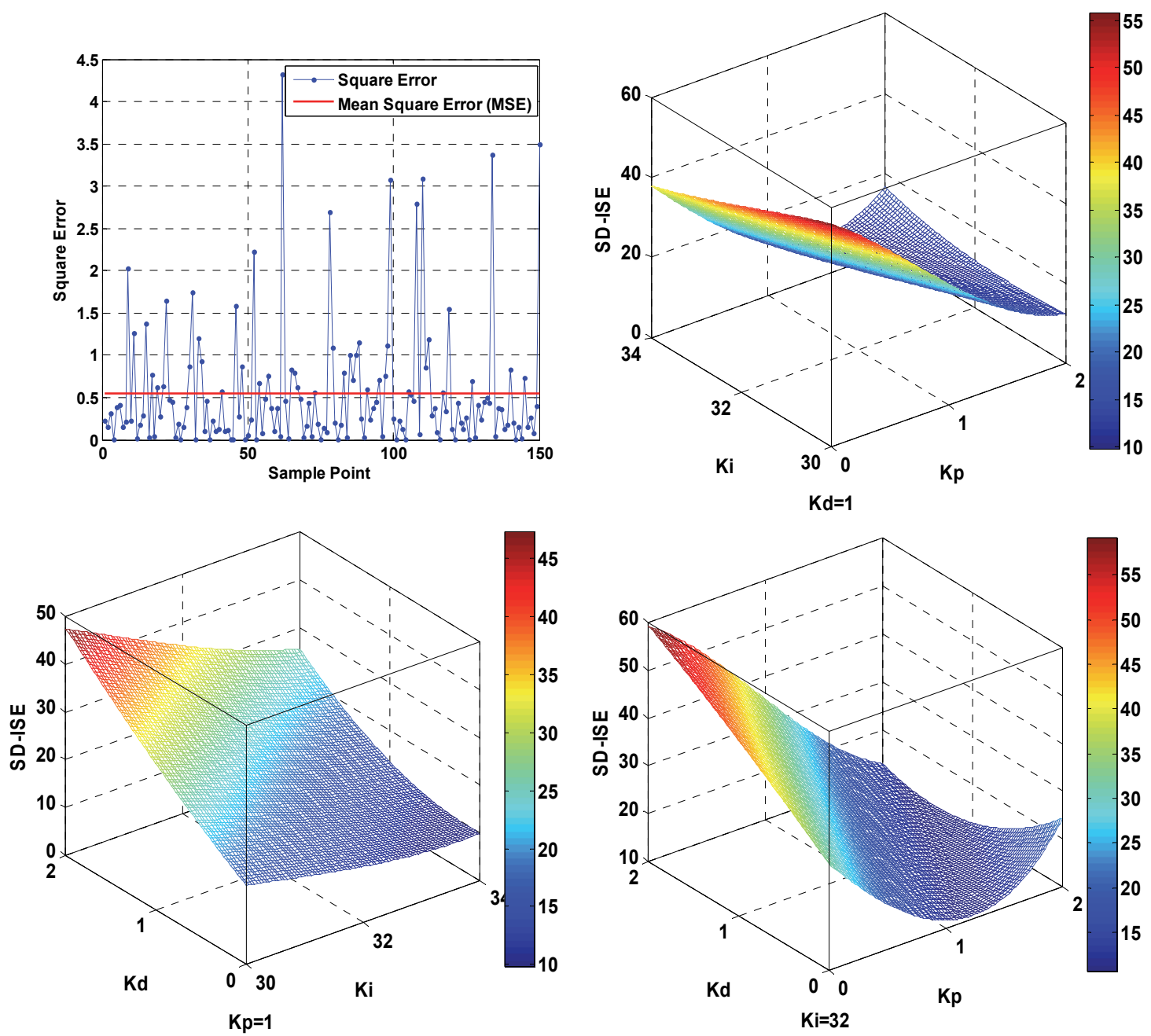

Fig. 9. The square error and 3D surface plots of fitted PR surrogate over SD of ISE. Surfaces plotted for two design variables (PID gain parameters) when third one stands on center of its design range.

We first define the initial best point by computing loss function values $\left(\overline{y_{S}}-T\right)^{2}+\sigma_{s}^{2}$ for each 150 sample points that were previously designed over the three design variables $\left(K_{p}, K_{i}, K_{d}\right)$ using the mean and SD values obtained in the predefined crossed array. The initial best point with less loss function has gain parameters as $K_{p}=1.279, K_{i}=32.578$, and $K_{d}=0.401$. Then, by employing both PR surrogate over the mean of ISE and SD of ISE and the obtained initial best point, we derive sequential robust design optimization. We define $\beta_{1}=0.2, \beta_{2}=0.01$, and $\beta_{3}=0.5$ to produce eight candidate points surrounding the current best point. Then, we derive sequential robust design optimization using Eq. (11) for 20 sequential runs, when in each run the candidate point with maximum $R E I(c)$ value (see Eq.(11)) is replaced with the current best point. The final result obtained after 20 sequential runs is as below:

$$
K_{p}=1.021, K_{i}=34.00 \text {, and } K_{d}=0.001
$$

The magnitudes of REI (Eq.(11)) and loss function for the best point among all the eight candidate points for each 20 sequential runs are illustrated in Fig. 10.

\subsection{Results and discussion}

Here, in order to show the preference of the proposed SOCI method in the robust tuning of the stochastic productioninventory control system, we compare the results obtained from PID tuning using SOCI method $\left(K_{p}=1.021, K_{i}=34.00\right.$, $\left.K_{d}=0.001\right)$ with MATLAB®/Simulink PID control toolbox and two metaheuristic techniques including the Particle Swarm Optimization (PSO) (Eberhart \& Kennedy, 1995) and Gray Wolf Optimizer (GWO) (Mirjalili et al., 2014) techniques that have been commonly used in tuning PID controller in the literature. We uniformly produce random numbers for uncertain variables (demand and frustrating rate) and tune the model with MATLAB ${ }^{\mathbb{R}} /$ Simulink, PID tuning toolbox and run both PSO and GWO metaheuristic methods. Accordingly, the optimal PID gain parameters are defined using 
MATLAB $^{\circledR} /$ Simulink, PID tuning toolbox as $K_{p}=0.08, K_{i}=31.98, K_{d}=0$ and using PSO and GWO methods with the same results as $K_{p}=2.00, K_{i}=34.00, K_{d}=0.47$.

We derive the comparison in two terms of less ISE measure (mean_ISE) and less variability or high robustness ( $\left.S D \_I S E\right)$. For this purpose, we first design 50 different combinations of uncertain variables (demand and frustrating rate) using the LHS method, and then for each optimal sets of gain parameters, the true simulation is run and relevant ISE is obtained, see Fig. 11. The obtained ISE values over these 50 combinations of uncertain variables provide mean and SD of ISE for a different set of PID gain parameters using proposed SOCI method, MATLAB ${ }^{\circledR} /$ Simulink PID control toolbox, PSO and GWO techniques. Table 2 depicts the comparison results of PID tuning with each method for the stochastic-dynamic P/I control system. In the current numerical case for stochastic production/inventory control system, the result shows that the PID tuning using SOCI method obtains less expected ISE (mean_ISE $=3.86$ ) as compared to tuning by PSO and GWO $($ mean_ISE $=8.03)$, and MATLAB ${ }^{\circledR} /$ Simulink PID control toolbox (mean_ISE $\left.=11.30\right)$. In the term of robustness against sources of variability (uncertainty) in ISE measure, the SOCI method depicted a better performance with smaller SD of ISE $\left(S D_{-} I S E=0.90\right)$ as compared to the tuning result obtained from PSO and GWO $\left(S D \_I S E=1.91\right)$, and MATLAB ${ }^{\circledR} /$ Simulink PID control toolbox $\left(S D_{-} I S E=2.62\right)$. In addition, for generating different combinations of two uncertain variables including demand rate and frustrating rate, we used the uniform random block in MATLAB ${ }^{\circledR} / \operatorname{Simulink}$ toolbox and uniformly produced random numbers in $[10,15]$ for $\widetilde{D}$ and $[0.02,0,05]$ for $\widetilde{\alpha}$.

\section{Table 2}

Optimal points derived through MATLAB/Simulink, PID tuning toolbox and proposed SOCI method for stochasticdynamic P/I control system

\begin{tabular}{|c|c|c|c|c|c|}
\hline \multirow{2}{*}{ Tuning method } & \multicolumn{3}{|c|}{ Gain parameters } & \multicolumn{2}{|c|}{ Performance (ISE) } \\
\hline & $K_{p}$ & $K_{i}$ & $K_{d}$ & Mean & SD \\
\hline SOCI & 1.021 & 34.000 & 0.001 & 3.86 & 0.90 \\
\hline PSO & 2.000 & 34.000 & 0.474 & 8.03 & 1.91 \\
\hline GWO & 2.000 & 34.000 & 0.474 & 8.03 & 1.91 \\
\hline MATLAB/Simulink, PID tuning toolbox & 0.079 & 31.985 & 0 & 11.30 & 2.62 \\
\hline
\end{tabular}

Fig. 12 shows the step response of the inventory level in the time domain $0 \leq t \leq 30$ with the time step-size 0.01 when the PID controller in the P/I control system is designed by each optimal sets of gain parameters obtained from each of the four optimization methods (see again Table 2). As can be seen in Fig. 12, the proposed SOCI method provides a more robust behaviour (insensitive) against a variability raised due to the uncertainty in the control system. For the current numerical case, we derive 50 simulation experiments based on the designed sample points for a five-dimensional optimization problem (three dimensions for three PID gain parameters and two dimensions for two uncertain variables). Here, we set 20 agents and a maximum of 100 iterations for both PSO and GWO techniques.
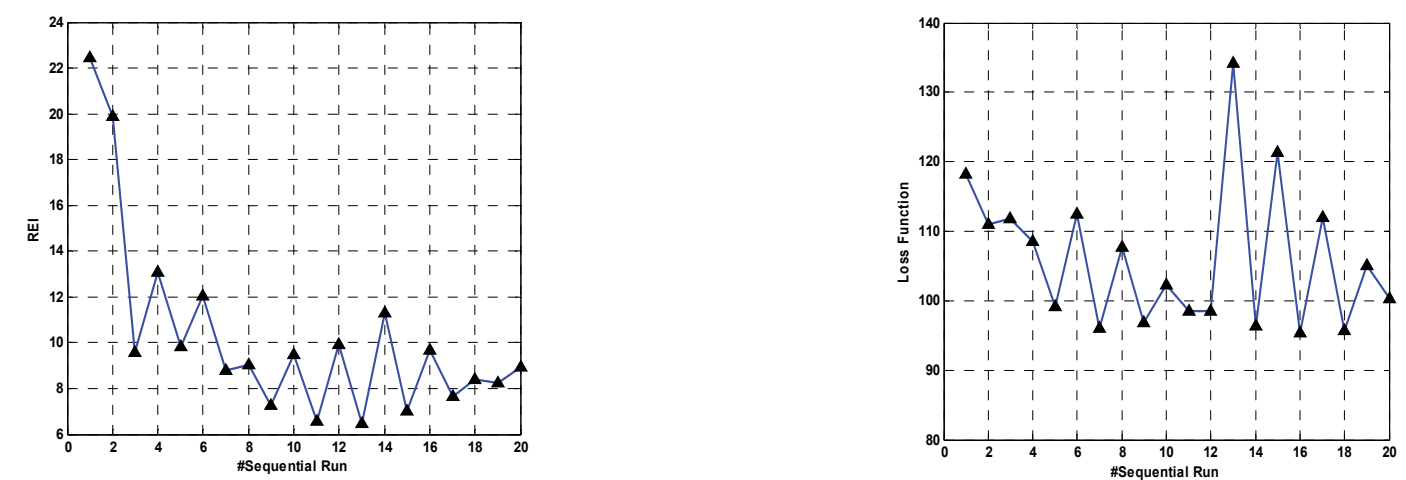

Fig. 10. The REI value and loss function value for the best sample point among all eight candidate points in each 20 sequential runs in robust efficient global optimization


Fig. 11. ISE values (used true simulation) over 50 different combinations of two uncertain variables (demand and Alfa) in production/inventory control system tuned with four methods, MATLABß/Simulink PID control toolbox, PSO, GWO and proposed SOCI method 
A number of simulation experiments (function evaluations) in metaheuristic techniques (e.g. model-based methods) strongly depend on problem dimension and significantly are larger than the size of simulation experiments in case of using surrogates (Wahab et al., 2015). Here, for more detailed comparisons, a number of function evaluations (original simulation runs) in existing studies using some common metaheuristic techniques for PID tuning in control systems (stochastic or deterministic) are compared with our proposed SOCI method, see Table 3.

\section{Table 3}

Number of simulation experiments (function evaluation) for optimal design of PID controller in SOCI and some modelbased methods in the literature

\begin{tabular}{|c|c|c|c|}
\hline Tuning Method & Reference & Engineering Design Problem & Number of Simulation Experiments (Function Evaluations) \\
\hline SOCI & This paper & $\begin{array}{l}\text { Robust optimal design of PID } \\
\text { controller in stochastic-dynamic } \\
\text { production-inventory control system. }\end{array}$ & $\begin{array}{l}\text { Total } 50 \text { simulation runs regarding combined array design for five } \\
\text { input variables (three design variables and two uncertain variables). }\end{array}$ \\
\hline PSO & This paper & $\begin{array}{l}\text { Tuning of PID gain parameters } \\
\text { (stochastic-dynamic production- } \\
\text { inventory control system). }\end{array}$ & 20 agents +50 maximum iterations \\
\hline GWO & This paper & $\begin{array}{l}\text { Tuning of PID gain parameters } \\
\text { (stochastic-dynamic production- } \\
\text { inventory control system). }\end{array}$ & 20 agents +50 maximum iterations \\
\hline GA & $\begin{array}{l}\text { (Jones \& } \\
\text { Hengue, } \\
2009)\end{array}$ & $\begin{array}{l}\text { MIMO-PID tuning for distillation } \\
\text { process }\end{array}$ & 50 initial population +1000 generations \\
\hline GA & $\begin{array}{l}\text { (Thomas \& } \\
\text { Poongodi, } \\
\text { 2009) }\end{array}$ & $\begin{array}{l}\text { Designing a position controller of a DC } \\
\text { motor by selection of PID gain } \\
\text { parameters }\end{array}$ & 60 initial populations +20 generations \\
\hline $\begin{array}{l}\text { Multi-objective } \\
\mathrm{ACO}\end{array}$ & $\begin{array}{l}\text { (Chiha et al., } \\
\text { 2012) }\end{array}$ & $\begin{array}{l}\text { Different simulations are analyzed for } \\
\text { getting good performances and tunes } \\
\text { the optimal PID parameters }\end{array}$ & 500 number of ants +300 maximum iterations \\
\hline $\begin{array}{l}\text { GA, EP, PSO, and } \\
\mathrm{ACO}\end{array}$ & $\begin{array}{l}\text { (Nagaraj \& } \\
\text { Murugananth, } \\
\text { 2010) }\end{array}$ & $\begin{array}{l}\text { A comparative study of PID controller } \\
\text { tuning by using Speed control of DC } \\
\text { motor process was used to assess the } \\
\text { comparison of all four algorithms. }\end{array}$ & 100 agents +100 maximum iterations \\
\hline
\end{tabular}

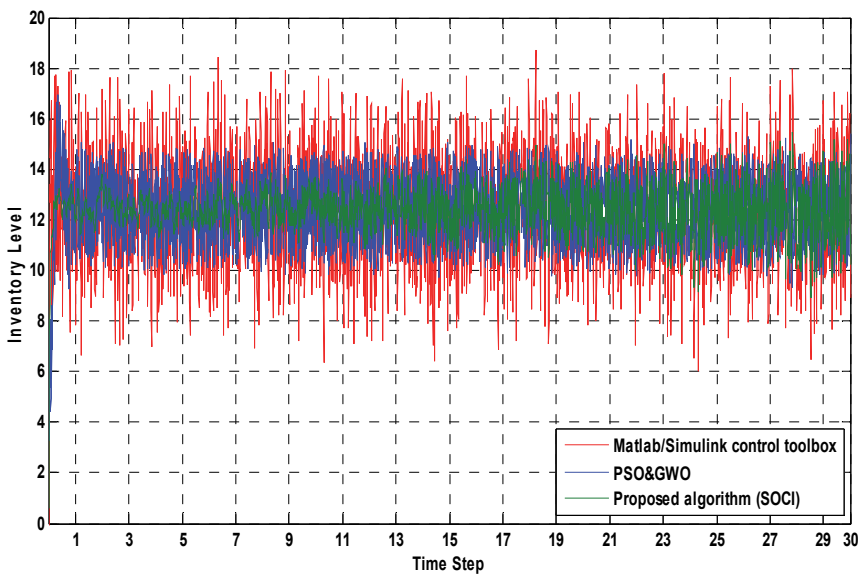

Fig. 12. Inventory level in time domain $0 \leq t \leq 30$ in the dynamic-stochastic $\mathrm{P} / \mathrm{I}$ control system when PID controller is tuned by four optimization methods, MATLAB ${ }^{\circledR} /$ Simulink PID control toolbox, PSO, GWO, and proposed SOCI method. The SOCI shows more robustness (less sensitive behaviour) against source of variability (uncertainty) in the model

\section{Conclusion}

This paper has introduced a dynamic-stochastic production/inventory control system by considering uncertainty in demand rate and frustrating rate. The main goal of the current study was to determine a new computational intelligence method in order to evaluate the production/inventory control system by designing robust optimal gain parameters of the proportionalintegral-derivative controller. The proposed computational intelligence method can be handled by crossing weighted uncertainty scenarios to targeting the unknown distribution of uncertainty. As another contribution of this paper, a new 
framework of robust efficient global optimization has been proposed in order to derive robust sequential efficient global improvement. The application and performances of the proposed approach are examined through a numerical example. The results indicate that the proposed method is proper for robust tuning of PID gain parameters in dynamic-stochastic control systems. The evidence from the findings suggests that the proposed method in this study can handle robust optimal designing of stochastic P/I control systems by less overall error (e.g. ISE) and robustness against the source of variability (e.g. uncertainty). In addition, the results of this study have indicated that the proposed method needs a smaller number of simulation experiments (computational cost) required for training of model and obtaining robust optimal results in contrast with some common evolutionary algorithms. Instead of polynomial regression in this study, it might be possible to use different surrogates such as Gaussian process regression, radial basis function, neural network, and support vector machine for future investigations. Further studies need to be carried out in order to expand the application of the proposed computational intelligence method in other control engineering design applications. Furthermore, the authors have targeted expanding the application of the proposed method in robust real-time optimization and control of Cyber-Physical Systems (CPS), see (Hu et al., 2016; Wang et al., 2018).

\section{Acknowledgement}

This research project is supported by the Second Century Fund (C2F), Chulalongkorn University.

\section{References}

Ab Wahab, M. N., Nefti-Meziani, S., \& Atyabi, A. (2015). A Comprehensive Review of Swarm Optimization Algorithms. PLOS ONE, 10(5), e0122827. 7

Agrell, P. J., \& Wikner, J. (1996). An MCDM framework for dynamic systems. International Journal of Production Economics, 45(1-3), 279-292.

Ali Asghar, B. (2019). Computational Intelligence and Its Applications in Uncertainty-Based Design Optimization. In Bridge Optimization-Inspection and Condition Monitoring. IntechOpen.

Ang, K. H., Chong, G., \& Li, Y. (2005). PID control system analysis, design, and technology. IEEE Transactions on Control Systems Technology, 13(4), 559-576.

Ansari, N., \& Hou, E. (2012). Computational intelligence for optimization. Springer Science \& Business Media.

Astrom, K. J., \& Hagglund, T. (1995). PID controllers: theory, design, and tuning (Vol. 2). Isa Research Triangle Park, $\mathrm{NC}$.

Åström, K. J., Hägglund, T., Hang, C. C., \& Ho, W. K. (1993). Automatic tuning and adaptation for PID controllers-a survey. Control Engineering Practice, 1(4), 699-714.

Azarskov, V. N., Skurikhin, V. I., Zhiteckii, L. S., \& Lypoi, R. O. (2013). Modern control theory applied to inventory control for a manufacturing system. IFAC Proceedings, 46(9), 1200-1205.

Azarskov, V. N., Zhiteckii, L. S., Solovchuk, K. Y., Sushchenko, O. A., \& Lupoi, R. O. (2017). Inventory Control for a Manufacturing System under Uncertainty: Adaptive Approach. IFAC-PapersOnLine, 50(1), 10154-10159.

Barros, M. F. M., Guilherme, J. M. C., \& Horta, N. C. G. (2010). Analog circuits and systems optimization based on evolutionary computation techniques (Vol. 294). Springer.

Camcioğlu, Ş., Özyurt, B., Doğan, İ. C., \& Hapoğlu, H. (2017). Application of response surface methodology as a New PID tuning method in an electrocoagulation process control case. Water Science and Technology, 76(12), 3410-3427.

Chen, S., \& Kuo, C. (2017). Design and Implement of the Recurrent Radial Basis Function Neural Network Control for Brushless DC Motor. Applied System Innovation (ICASI), 2017 International Conference IEEE, 562-565.

Chiha, I., Liouane, N., \& Borne, P. (2012). Tuning PID Controller Using Multiobjective Ant Colony Optimization. Applied Computational Intelligence and Soft Computing, 2012(1), 1-7.

Cohen, Gh. (1953). Theoretical consideration of retarded control. Trans. Asme, 75, 827-834.

Dejonckheere, J., Disney, S. M., Lambrecht, M. R., \& Towill, D. R. (2003). Measuring and avoiding the bullwhip effect: A control theoretic approach. European Journal of Operational Research, 147(3), 567-590.

Del Castillo, E., \& Montgomery, D. C. (1993). A nonlinear programming solution to the dual response problem. Journal of Quality Technology, 25, 199-204.

Dellino, G., Lino, P., Meloni, C., \& Rizzo, A. (2009). Kriging metamodel management in the design optimization of a CNG injection system. Mathematics and Computers in Simulation, 79(8), 2345-2360.

Eberhart, R., \& Kennedy, J. (1995). Particle swarm optimization. Proceedings of the IEEE International Conference on Neural Networks, 4, 1942-1948.

Faruq, A., Shah, M. F. N., \& Abdullah, S. S. (2018). Multi-objective optimization of PID controller using pareto-based surrogate modeling algorithm for MIMO evaporator system. International Journal of Electrical and Computer Engineering, 8(1), 556.

Figueira, G., \& Almada-Lobo, B. (2014). Hybrid simulation optimization methods a taxonomy and discussion. Simulation Modelling Practice and Theory, 46, 118-134.

Garcia Salcedo, C. A., Ibeas Hernandez, A., Vilanova, R., \& Herrera Cuartas, J. (2013). Inventory control of supply chains: Mitigating the bullwhip effect by centralized and decentralized Internal Model Control approaches. European Journal of Operational Research, 224(2), 261-272.

Grubbström, R. W., \& Wikner, J. (1996). Inventory trigger control policies developed in terms of control theory. International Journal of Production Economics, 25(1-3), 397-406. 
Hang, C. C., Åström, K. J., \& Ho, W. K. (1991). Refinements of the Ziegler-Nichols tuning formula. IEE Proceedings D (Control Theory and Applications), 138(2), 111-118.

Hasani, A., Eskandarpour, M., \& Fattahi, M. (2018). A simulation-based optimisation approach for multi-objective inventory control of perishable products in closed-loop supply chains under uncertainty. International Journal of Advanced Operations Management, 10(4), 324-344.

Havinga, J., van den Boogaard, A. H., \& Klaseboer, G. (2017). Sequential improvement for robust optimization using an uncertainty measure for radial basis functions. Structural and Multidisciplinary Optimization, 55(4), $1345-1363$.

Ho, T., Chen, Y., Chen, P., \& Hu, P. (2017). The Design of a Motor Drive Based on Neural Network. Applied System Innovation (ICASI), 2017 International Conference IEEE, 337-340.

Hu, F., Lu, Y., Vasilakos, A. V., Hao, Q., Ma, R., Patil, Y., Zhang, T., Lu, J., Li, X., \& Xiong, N. N. (2016). Robust CyberPhysical Systems: Concept, models, and implementation. Future Generation Computer Systems, 56, 449-475.

Hwang, K.-Y., Rhee, S.-B., Yang, B.-Y., \& Kwon, B.-I. (2007). Rotor Pole Design in Spoke-Type Brushless DC Motor by Response Surface Method. IEEE Transactions on Magnetics, 43(4), 1833-1836.

Jin, R., Chen, W., \& Simpson, T. W. (2001). Comparative studies of metamodelling techniques under multiple modelling criteria. Structural and Multidisciplinary Optimization, 23(1), 1-13.

Jones, K. O., \& Hengue, W. (2009). Limitations of multivariable controller tuning using genetic algorithms. Proceedings of the International Conference on Computer Systems and Technologies and Workshop for PhD Students in Computing, 46.

Jurecka, F, Ganser, M., \& Bletzinger, K. U. (2007). Update scheme for sequential spatial correlation approximations in robust design optimisation. Computers and Structures, 85(10), 606-614.

Jurecka, Florian. (2007). Robust Design Optimization Based on Metamodeling Techniques. PhD Thesis.

Liu, X., Li, M., \& Xu, M. (2016). Kriging assisted on-line torque calculation for brushless DC motors used in electric vehicles. International Journal of Automotive Technology, 17(1), 153-164.

Liu, Xiang, Ma, C., Li, M., \& Xu, M. (2011). A kriging assisted direct torque control of brushless DC motor for electric vehicles. Natural Computation (ICNC), 2011 Seventh International Conference on, IEEE, 3(July), 1705-1710.

McKay, M. D., Beckman, R. J., \& Conover, W. J. (1979). Comparison of three methods for selecting values of input variables in the analysis of output from a computer code. Technometrics, 21(2), 239-245.

Meshram, P. M., \& Kanojiya, R. G. (2012). Tuning of PID Controller using Ziegler-Nichols Method for Speed Control of DC Motor. 2013 IEEE International Conference on Control Applications (CCA), 117-122.

Mirjalili, S., Mirjalili, S. M., \& Lewis, A. (2014). Grey Wolf Optimizer. Advances in Engineering Software, 69, 46-61.

Myers, R., C.Montgomery, D., \& Anderson-Cook, M, C. (2016). Response Surface Methodology: Process and Product Optimization Using Designed Experiments-Fourth Edittion. John Wiley \& Sons.

Nagaraj, B., \& Murugananth, N. (2010). A comparative study of PID controller tuning using GA, EP, PSO and ACO. Communication Control and Computing Technologies (ICCCCT), 2010 IEEE International Conference, October, 305313.

Nakayama, H., Arakawa, M., \& Sasaki, R. (2002). Simulation-based optimization using computational intelligence. Optimization and Engineering, 3(2), 201-214.

Neck, R. (1984). Stochastic control theory and operational research. European Journal of Operational Research, 17(3), 283-301.

Ortega, M., \& Lin, L. (2004). Control theory applications to the production-inventory problem: A review. International Journal of Production Research, 42(11), 2303-2322.

Parnianifard, A, Azfanizam, A., Ariffin, M., Ismail, M., \& Ebrahim, N. (2019). Recent developments in metamodel based robust black-box simulation optimization: An overview. Decision Science Letters, 8(1), 17-44.

Parnianifard, A, Azfanizam, A. S., Ariffin, M. K. A., \& Ismail, M. I. S. (2018). Kriging-Assisted robust black-box simulation optimization in direct speed control of DC motor under uncertainty. IEEE Transactions on Magnetics, 54(7), $1-10$.

Parnianifard, Amir, Azfanizam, A. S., Ariffin, M. K. A., \& Ismail, M. I. S. (2018a). An overview on robust design hybrid metamodeling: Advanced methodology in process optimization under uncertainty. International Journal of Industrial Engineering Computations, 9(1), 1-32.

Parnianifard, Amir, Azfanizam, A. S., Ariffin, M. K. A., \& Ismail, M. I. S. (2018b). Design and analysis of computer experiments using polynomial regression and latin hypercube sampling in optimal design of PID controller. Journal of Applied Research on Industrial Engineering, 5(2), 156-168.

Parnianifard, Amir, Azfanizam, A. S., Ariffin, M. K. A., \& Ismail, M. I. S. (2019a). Crossing weighted uncertainty scenarios assisted distribution-free metamodel-based robust simulation optimization. Engineering with Computers, 36(1), 139150.

Parnianifard, Amir, Azfanizam, A. S., Ariffin, M. K. A., \& Ismail, M. I. S. (2019b). Comparative study of metamodeling and sampling design for expensive and semi-expensive simulation models under uncertainty. SIMULATION, 96(1), 89110.

Parnianifard, Amir, Azfanizam, A. S., Ariffin, M. K., Ismail, M. I., Maghami, M. R., \& Gomes, C. (2018). Kriging and Latin hypercube sampling assisted aimulation optimization in optimal design of PID controller for speed control of DC motor. Journal of Computational and Theoretical Nanoscience, 15(5), 1471-1479.

Phadke, M. S. (1989). Quality Engineering Using Robust Design. Prentice Hall PTR. 
Pishvaee, M. S., Rabbani, M., \& Torabi, S. A. (2011). A robust optimization approach to closed-loop supply chain network design under uncertainty. Applied Mathematical Modelling, 35(2), 637-649.

Rivera, D. E., \& Pew, M. D. (2005). Evaluating PID control for supply chain management: A freshman design project. Proceedings of the 44th IEEE Conference on Decision and Control, and the European Control Conference, CDC-ECC '05, Dece, 3415-3419.

Rutten, K. (2015). Methods For Online Sequential Process Improvement. PhD Thesis.

Ryabchikov, M. Y., \& Ryabchikova, E. S. (2017). Optimizing control system based on integration of competing search optimization algorithms. 2017 International Conference on Industrial Engineering, Applications and Manufacturing (ICIEAM), 1-6.

Sacks, J., Welch, W. J., Mitchell, T. J., \& Wynn, H. P. (1989). Design and analysis of computer experiments. Statistical Science, 4, 409-435.

Schwartz, J. D., \& Rivera, D. E. (2010). A process control approach to tactical inventory management in productioninventory systems. International Journal of Production Economics, 125(1), 111-124.

Sethi, S. P. (2019). Optimal Control Theory-Applications to Management Science and Economics-3th Edittion. In Optimal Control Theory. Springer International Publishing.

Shah, M. F. N., Zainal, M. A., Faruq, A., \& Abdullah, S. S. (2011). Metamodeling approach for PID controller optimization in an evaporator process. 2011 th International Conference on Modeling, Simulation and Applied Optimization, ICMSAO 2011, 5-8.

Sóbester, A., Leary, S. J., \& Keane, A. J. (2004). A parallel updating scheme for approximating and optimizing high fidelity computer simulations. Structural and Multidisciplinary Optimization, 27(5), 371-383.

Sourirajan, K., Ramachandran, B., \& An, L. (2008). Application of control theoretic principles to manage inventory replenishment in a supply chain. International Journal of Production Research, 46(21), 6163-6188.

Tang, L., Ma, Y., Wang, J., Ouyang, L., \& Byun, J.-H. (2019). Robust parameter design of supply chain inventory policy considering the uncertainty of demand and lead time. Scientia Iranica, 26(5), 2971-2987.

Tao, Y., Lee, L. H., Chew, E. P., Sun, G., \& Charles, V. (2017). Inventory control policy for a periodic review system with expediting. Applied Mathematical Modelling, 49, 375-393.

Tenne, Y., \& Goh, C.-K. (2010). Computational intelligence in expensive optimization problems (Vol. 2, Issue March). Springer Science \& Business Media.

Thomas, N., \& Poongodi, P. (2009). Position control of DC motor using genetic algorithm based PID controller. Proceedings of the World Congress on Engineering, 2, 1-3.

Towill, D. R., \& Yoon, S. S. (1982). Some features common to inventory system and process controller design. Engineering Costs and Production Economics, 6(April), 225-236.

Van Landeghem, H., \& Vanmaele, H. (2002). Robust Planning: A New Paradigm for Demand Chain Planning. Journal of Operations Management, 20(6), 769-783.

Viana, F. A. C. (2016). A tutorial on latin hypercube design of experiments. Quality and Reliability Engineering International, 32(5), 1975-1985.

Wang, G., \& Shan, S. (2007). Review of metamodeling techniques in support of engineering design optimization. Journal of Mechanical Design, 129(4), 370-380.

Wang, Q.-G., Lee, T.-H., Fung, H.-W., Bi, Q., \& Zhang, Y. (1999). PID tuning for improved performance. IEEE Transactions on Control Systems Technology, 7(4), 457-465.

Wang, W., Di Maio, F., \& Zio, E. (2018). Hybrid fuzzy-PID control of a nuclear Cyber-Physical System working under varying environmental conditions. Nuclear Engineering and Design, 331(December 2017), 54-67.

White, A S. (1999). Management of inventory using control theory. International Journal of Technology Management, 17(7-8), 847-860.

White, Anthony S, \& Censlive, M. (2016). Inventory Control Systems Model for Strategic Capacity Acquisition. Journal of Industrial Engineering.

Wikner, J. (1994). Dynamic modelling and analysis of information flows in production-inventory and supply chain systems. Profil, Linköping,

Ziegler, J. G., \& Nichols, N. B. (1942). Optimum settings for automatic controllers. Trans. ASME, 64(11). 
(C) 2020 by the authors; licensee Growing Science, Canada. This is an open access article distributed under the terms and conditions of the Creative Commons Attribution (CC-BY) license (http://creativecommons.org/licenses/by/4.0/). 